\title{
O campo da educação no Brasil: mudanças em atributos para legitimação dos pesquisadores
}

The field of education in Brazil: changes in attributes for legitimation of
researchers

El campo de la educación en Brasil: cambios en atributos para la legitimación

de los investigadores

CÉLIA ELIZABETE CAREGNATO

BERNARDO SFREDO MIORANDO

DENISE LEITE

Resumo: $\mathrm{O}$ artigo discute como os pesquisadores constroem a legitimidade científica no campo da educação no Brasil. Estratégias e disputas compõem a dinâmica e permitem analisar a obtenção de capital científico puro e político. A metodologia incluiu a análise de currículos e evidencia que, frente à busca por produtividade e legitimidade, entre 2005 e 2014, houve mudança na composição do capital acadêmico-científico dos atores, provavelmente induzida pelas políticas públicas de avaliação.

Palavras-chave: universidade; campo acadêmico-científico; pesquisa em educação; avaliação.

Abstract: This article discusses how researchers build their scientific legitimacy in the field of education in Brazil. Strategies and disputes mark the dynamics and offer elements to analyze the acquisition of political and pure scientific capital. The methodology included analysis of researchers' curricula and shows that, vis-à-vis the quest for productivity and legitimacy, in the time elapsed between 2005 and 2014, there was a change in the composition of the players' academicscientific capital, probably induced by the evaluation public policies in the last decades.

Keywords: university; academic-scientific field; educational research; evaluation.

Resumen: El artículo discute cómo los investigadores construyen la legitimidad científica en el campo de la educación en Brasil. Estrategias y disputas componen la dinámica y permiten analizar la obtención de capital científico puro y político. La metodología incluyó el análisis de currículos y muestra que, ante la búsqueda por productividad y legitimidad, entre 2005 y 2014, hubo cambio en la composición del capital académico-científico de los actores, probablemente inducido por las políticas públicas de evaluación.

Palabras clave: universidad; campo académico-científico; investigación en educación; evaluación. 


\section{INTRODUÇÃO}

Em muitas áreas do conhecimento, a pesquisa científica no Brasil se desenvolveu e se consolidou junto à instituição dos programas de pósgraduação. Esse fenômeno produziu uma identificação muito grande entre os campos acadêmico e científico, de modo que, para abordar o campo científico brasileiro, é preciso voltar os olhos para as universidades. Ao buscar seus atores, os pesquisadores, encontramos docentes de pós-graduação. Essa sobreposição é ratificada pelo Conselho Nacional de Desenvolvimento Científico e Tecnológico (CNPq), que coloca entre os critérios para a definição de seus bolsistas de produtividade em pesquisa em educação a atuação na pós-graduação.

Se tomarmos a pós-graduação como medida do campo acadêmicocientífico, percebemos que a educação ocupa nele lugar significativo. Com 3.863 docentes, é a quarta área com mais pesquisadores seniores, atrás apenas de Ciências Agrárias, Interdisciplinar e Letras/Linguística. Foi a área que mais conferiu diplomas de mestrado, a segunda com maior número de egressos do doutorado (CAPES, 2016). Não obstante, se esses números dão ideia do tamanho que a área da educação ocupa na academia brasileira, eles não incorporam ou transmitem a complexidade e a heterogeneidade que caracterizam a área.

A área da Educação é entendida neste estudo como um subcampo no interior das ciências humanas, segmento do campo acadêmico-científico, a fim de que se possa interpretar traços da atuação daqueles que são seus pesquisadores de referência e produtores de conhecimento legitimado pelas agências de financiamento e classificação. Ela se constrói como um subcampo acadêmico-científico especialmente híbrido, uma vez que se produz pela interação e entrecruzamento de teorias oriundas de diferentes campos de conhecimento com atividades acadêmico-científicas e intervenções diretas de aplicabilidade no sistema educacional. O subcampo da educação, de maneira própria, requer que os agentes desempenhem em funções políticas e em ações públicas de intervenção que vão além da política estritamente científica e/ou acadêmica (FARIA FILHO, 2016). Nomeadamente, os pesquisadores estão envolvidos na formulação, implementação e avaliação de políticas de educação, infantil, básica e superior, tanto quanto estão empenhados na produção científica do campo.

Um subcampo com um número tão vasto de atores, com tantos mais ingressando a cada ano, pareceria necessitar de regras claras para orientar a atuação e a concorrência por recursos em seu seio. Para investigar essa dinâmica, partimos de perguntas simples entendendo que o sentido do empírico é inesgotável, ou seja, "algo a ser permanentemente compreendido e de maneira diferente a cada situação" pois que, "quem quer pensar deve perguntar-se" como diz Dalbosco 
(2014, p. 1037). Nesse sentido, e na busca de novos arranjos explicativos para problemas antigos, seguimos Bourdieu (1996). Nossa intencionalidade se justifica porque tem a ver com a convicção de que "não podemos capturar a lógica mais profunda do mundo social a não ser submergindo na particularidade de uma realidade empírica, situada e datada, para construí-la (...) como um universo de configurações possíveis" (p. 15). Que atores são referência no subcampo educação? Como produzem cientificamente? Que mudanças estão a acontecer no subcampo acadêmico-científico da educação?

Tomamos como referência da área os pesquisadores bolsistas de produtividade em pesquisa do Conselho Nacional de Desenvolvimento Científico e Tecnológico (CNPq) enquadrados na categoria mais alta da escala em período determinado. Essa categoria foi o ponto de partida porque abrange acadêmicos que recebem uma subvenção federal "destinada aos pesquisadores que se destaquem entre seus pares, valorizando sua produção científica segundo critérios normativos, estabelecidos pelo CNPq, e específicos, pelos Comitês de Assessoramento (CAs) do CNPq" (CNPQ, 2015, item 1). De modo geral, todos os CAs devem adotar como critérios:

a) mérito científico do projeto; b) relevância, originalidade e repercussão da produção científica do candidato; c) formação de recursos humanos em nível de Pós-Graduação; d) contribuição científica, tecnológica e de inovação, incluindo patentes; e) coordenação ou participação em projetos e/ou redes de pesquisa; f) inserção internacional do proponente; g) participação como editor científico; h) participação em atividades de gestão científica e acadêmica (Idem, item 3.4).

Buscamos ler os indícios de suas práticas e produções expressos por registros em seus currículos Lattes. Esses dados nos permitiram compilar indícios de capital científico e político, sinalizando perfis de pesquisadores e possíveis estratégias de composição de carreira por um grupo delimitado de pesquisadores de referência no subcampo. O amplo escopo da área de educação e de programas de pós-graduação em Educação no Brasil, combinado com a forte normatização para avaliação dos professores e pesquisadores, indicam que se trata de um campo de produção e disseminação do conhecimento acadêmico-científico detentor de complexidade própria e que merece atenção. Interpretamos aspectos de suas estratégias de acumulação de capital cientifico por meio de informações disponíveis no currículo Lattes dos pesquisadores, tais como sua produção, formação e ocupação de cargos. Para tanto, buscamos esclarecer os elementos teóricos e contextuais que permitem lidar com a noção de campo no caso em questão. 


\section{UM (SUB) CAMPO COM AUTONOMIA PRECÁRIA}

Pierre Bourdieu $(1983$; 2004) define o campo científico a partir de possibilidades de estratégias e disputas em busca do prestígio, mostrando a dinâmica contraditória no seu interior e oferecendo elementos para analisar aquilo que o compõe na forma de capital cientifico puro e de capital político.

O primeiro está ligado ao reconhecimento do pesquisador junto aos pares-concorrentes, o que diz respeito, portanto, ao acúmulo de capital simbólico no interior do campo a partir de sua capacidade de produzir conhecimentos e fazê-los repercutir. O segundo está vinculado à inserção dos pesquisadores em posições tidas como importantes e em cargos de gerência nas instituições científicas, comandando, assim, dinâmicas de definição das regras do jogo.

No caso do capital político no interior do campo científico, tais posições podem incluir, entre outras, direção de laboratórios, unidades acadêmicas ou departamentos, comitês de avaliação. Representam, dessa forma, o poder sobre os meios de produção - contratos, créditos, postos, acessos a espaços, informações, contatos e recursos materiais - e de reprodução - poder de nomear e fazer carreiras, por exemplo.

Classicamente, compreende-se que, sendo um campo social como qualquer outro, ele é permeado por lutas concorrenciais, relações de força, monopólios, estratégias, interesses e lucros (BOURDIEU, 1983; 2004). O que está em jogo, diz o autor, é o monopólio da competência científica, ou seja, a capacidade de agir e falar legitimamente para o campo e em nome dele.

Os pesquisadores, nas diversas áreas ou campos, optam pelos meios que permitam maximizar ganhos. Isso ocorre também na experiência brasileira de organização da ciência, especialmente por meio das avaliações externas, que pontuam e classificam pessoas, oferecem prêmios e punições. De fato, no mais das vezes, as condições para o desenvolvimento de novas pesquisas são dependentes dos resultados dessas avaliações. Esse é o caso da aprovação de projetos de pesquisa por órgãos financiadores, o que garante recursos materiais para capital, custeio, bolsas de estudos e, ainda, permite a fruição de períodos sabáticos, renovadores das possibilidades de atuação profissional em pesquisa. Da mesma forma, a avaliação dos programas de pós-graduação, principal lócus da produção de conhecimento científico no Brasil, constitui-se em fator estruturante que define regras do cenário institucional em que se posicionam os agentes.

Portanto, reconhecer a produção e os lugares ocupados pelos pesquisadores em atividades da vida acadêmica permite aproximarmo-nos de elementos que evidenciam perfis no campo. Mesmo no interior desse sistema tido como unificado, há diferentes modos de conceber, planejar e realizar pesquisas. 
Essa busca nos auxilia a identificar aspectos que aproximam ou distanciam pesquisadores situados em diferentes posições.

Focalizamos os pesquisadores de prestígio, ou seja, aqueles chancelados pelos pares e que receberam classificação superior na escala de bolsas do CNPq. Vimos que o campo da Educação ocupa importante espaço institucional e se organiza no entrelaçamento com lógicas típicas de outros campos científicos. Ele conta com pesquisadores destacados que desenvolvem suas atividades de forma heterogênea e com orientações próprias, dentro dos limites do campo, não só quanto a seus objetos e metodologias, mas também quanto à forma de conceber e operar grupos, redes de trabalho e estratégias para operacionalizar a produção.

Para apreender a complexidade multiparadigmática das formas de produzir conhecimento pela pesquisa em Educação é fundamental analisar as práticas desses pesquisadores e seus resultados. Uma vez que os sistemas simbólicos se distinguem fundamentalmente se forem produzidos pelo conjunto de um grupo ou por um grupo de especialistas, assumimos como necessário reconhecer o habitus (BOURDIEU, 2000; 2011), como formas de produzir e de se relacionar que podem ser recorrentes e revelar microestruturas e relações sobre o modo de fazer pesquisa na área.

Os habitus são princípios geradores de práticas distintas e distintivas (...) mas são também esquemas classificatórios, princípios de classificação, princípios de visão e de divisão e gostos diferentes. (...) Assim, por exemplo, o mesmo comportamento ou o mesmo bem pode parecer distinto para um, pretensioso ou ostentatório para outro e vulgar para um terceiro (BOURDIEU, 1996, p. 22).

As diferenças nas práticas e bens possuídos, e nas opiniões expressas, tornam-se diferenças simbólicas que servem tanto para classificar como para ser classificado.

No espectro mais amplo, de intensificação da competitividade nacional e internacional, quanto ao desempenho e a resultados da produção acadêmica (CAPES, 2013), consideramos relevante verificar o conjunto de mudanças que vão ocorrendo no subcampo e que incidem sobre formas pelas quais os pesquisadores percebem, classificam e agem ao fazer ciência e suscitam rearticulações entre habitus e campo. A competitividade acadêmica e a avaliação externa mais presentes, em relação a períodos anteriores, geram modificações no interior do sistema de produção acadêmica, mas também podem gerar alterações nas regras de atuação no campo.

No Brasil, o subcampo da pesquisa em educação é estruturado sobre o espaço da pós-graduação de tal modo que talvez sejam as políticas voltadas para essa atividade as que mais impactam suas dinâmicas (FARIA FILHO, 2016). 
Ocorre que, para atuar sobre o sistema, tais políticas se compõem a partir da avaliação da produtividade individual dos pesquisadores, determinando, via condicionamento do financiamento, quem pode ser considerado e atuar como pesquisador. Entendemos, então, que as mudanças nas dinâmicas do campo podem ser captadas a partir das estratégias individuais que utilizam os pesquisadores, como agentes em luta, para defender e avançar suas posições no campo.

A teoria sociológica de Bourdieu estabelece a compreensão de que o habitus tende a reproduzir práticas, mas também lida com a interpretação de que não se trata de comportamentos estanques, e sim de relações sociais que são contextualizadas fazendo com que os mesmos referenciais compartilhados pelos atores possam produzir respostas que se modificam com mutações na correlação de fatores envolvidos (BOURDIEU, 1996; SETTON, 2002; BECK; YOUNG, 2008). Trabalhamos com a hipótese de que há mudanças importantes nas práticas em uso no campo e, talvez, no habitus, podendo evidenciar, até, novas pequenas nuanças nos contornos epistemológicos do subcampo da Educação.

O subcampo, como sistema dinâmico, vai reafirmando ou redefinindo o capital específico que representa a legitimidade do pesquisador através dos deslocamentos empreendidos para alterar a relação de força histórica entre agentes e instituições presentes no campo ou do esforço pela manutenção das regras existentes (BOURDIEU, 2004). Essas estratégias de luta vão compondo as trajetórias dos agentes, que servem como registros

não-lineares a partir dos quais se pode apreender tendências emergentes das tensões no campo.

Para nosso estudo, além de reconhecer o conjunto de força e contradição capaz de compor o subcampo específico, tomamos como ponto de partida o reconhecimento de que a ciência possui uma autonomia relativa a partir da qual ela pode ser pensada. Como observa Bourdieu (2004), quanto mais delimitado e competitivo o campo, quanto mais bem definida a linguagem de um campo científico, maior a autonomia do campo. Essa autonomia, portanto, também está ligada à capacidade de determinar um capital distintivo, uma diferença, que pode orientar o campo com sua capacidade de ser visto como específico, escasso e de difícil produção. Nesse caso, os cientistas falam geralmente para auditórios mais seletivos e restritos. Este não parece ser o caso do campo da educação (LEITE et al., 2014; CAREGNATO; LEITE; SFREDO MIORANDO, 2016).

Trabalhamos com o pressuposto de que o conhecimento em educação lida com realidades contextuais; portanto, tende a afastar-se do ideal de ciência que produz teorias universalmente válidas e constrói uma linguagem precisa e hermética. No entanto, o subcampo da educação é atravessado pelas disputas políticas decorrentes de seus objetos de investigação e de sua condição de prática 
social. No Brasil, como tende a ocorrer com as ciências humanas, está também situado de forma subalterna em relação a outros subcampos científicos, com menos condições de disputar posições de tomada de decisão do que outras ciências e com uma atribuição de recursos de ordem inferior (BARATA et al., 2014). Além disso, as práticas de divulgação científica a que recorre para sustentar seu capital científico limitam suas possibilidades de inserção internacional e reconhecimento no campo (FIORIN, 2007).

Ainda, o fato de que "os sujeitos estabelecem a legitimidade de suas posições não a partir do campo acadêmico-científico, mas a partir das razões políticas e ideológicas" (FARIA FILHO, 2016, p. 188) expressa-se como uma das importantes regras que caracterizam o campo. O subcampo da Educação tende ainda a estar em situação de maior heteronomia em relação a outros já que aplica à sua avaliação critérios definidos por outros subcampos acadêmico-científicos (JAPIASSU, 2013; KUENZER; MORAES, 2005; HORTA; MORAES, 2005; LEITE, 2002).

Ao mesmo tempo, critérios próprios que anuncia como relevantes, como é o caso da inserção social por meio de extensão, produção de material didático e parcerias com as redes de ensino, parecem ter dificuldade de se consolidar (RISTOFF; BIANCHETTI, 2012). Esses critérios são utilizados para avaliação dos programas de pós-graduação (CAPES, 2013), mas não para a avaliação da produção dos pesquisadores. Isso pode ser constatado, inclusive, por meio dos registros nos currículos analisados, que, de um modo geral não registram esse tipo de produção.

\section{METODOLOGIA}

Para constituir o corpo de dados em análise neste trabalho, tomamos como delimitação inicial os pesquisadores que recebiam bolsa de produtividade do CNPq na categoria mais elevada em janeiro de 2015. Uma vez que nossos interesses de pesquisa se voltavam para as relações desses pesquisadores com seus colegas e orientandos, e pela forma como essas relações poderiam estruturar o campo, decidimos trabalhar com aqueles que, naquele momento, liderassem grupos de pesquisa registrado no Diretório Geral de Grupos de Pesquisa do CNPq com, no mínimo, dez anos de existência. Esse recorte inicial nos levou a 21 pesquisadores, cujos currículos na Plataforma Lattes foram congelados para estudo. Assim, é importante registrar que os dados aos quais nos referimos têm abrangência temporal fixada até, inclusive, 2014. Colocamos especial atenção sobre os dez anos que antecederam a pesquisa, ou seja, o período 2005-2014. Essa decisão foi tomada considerando as possibilidades de comparação com 
pesquisa anterior, em que analisamos, para o período de 2001-2010, a atuação de outros pesquisadores do CNPq na área da Educação. Igualmente, reportamonos sempre ao que foi informado pelos pesquisadores em seus currículos Lattes, fazendo a ressalva de que a carreira dos acadêmicos em questão pode incluir outras atividades que não estavam registradas por eles nesses documentos.

Através dos currículos, estudamos as carreiras desses pesquisadores, colocando especial atenção sobre algumas categorias de itens que julgamos propícios para identificar icapital acadêmico-científico puro e político. Esses itens identificam as trocas simbólicas objetivadas por esse capital e visualizadas através das avaliações nas quais "o silêncio a respeito da verdade da troca é um silêncio compartilhado" (BOURDIEU, 1996, p. 163). Também tivemos presente a significativa influência da avaliação da pós-graduação desempenhada pela Comissão de Aperfeiçoamento de Pessoal de Nível Superior (Capes) nas práticas de produção e veiculação do conhecimento no Brasil. Desse modo, apuramos a atuação dos pesquisadores quanto aos seguintes quesitos: formação doutoral, produção científica, cargos e funções acadêmicas desempenhados, participação em órgãos de fomento e regulação. Examinamos também outras atividades ligadas ao acúmulo de capital acadêmico-científico e político. Consideramos também a dimensão internacional. Outros elementos, como veículos de publicações utilizados, orientações realizadas, coautorias e afiliações institucionais dos coautores também foram coletados, mas não serão explorados neste trabalho.

Analisamos a produção científica de pesquisadores de referência na educação. Temos em mente que alguns dos sujeitos podem, mesmo, ter desempenhado grande influência na configuração do subcampo, alcançando autoridade tradicional na área. Consideramos a diferenciação do grupo de 21 indivíduos em duas coortes: um grupo " $\mathrm{A}$ " constituído por dez pesquisadores em educação (PEA) que contavam com bolsa de produtividade de alto nível em 2010; e um grupo "B" de doze pesquisadores em educação (PEB), que acessou a mesma categoria após essa data, entre 2011 e 2014. Foi examinada a produção de 2005 a 2014 do grupo PEA e do grupo PEB.

\section{APRESENTAÇÃO DOS RESULTADOS}

Entendemos que o perfil de carreira apresentado pelos pesquisadores que fizeram parte da amostra, atende ao declarado nos critérios de um edital de uma agência financiadora como o CNPq (2015, Item 1) e seja oriundo de seu habitus profissional. Esse perfil pode contribuir para compor um arquétipo, um ideal do que é um pesquisador da educação, ou do que deve ser. Tal como explica Bourdieu (1996), "tendo interiorizado a lei imanente da estrutura (seu conatus) sob a forma 
de um habitus, os agentes podem parecer de certo modo ausentes de sua prática, quando cumprem com as exigências da estrutura no movimento espontâneo de sua existência" (p.161). Dessa forma, quando profissionais da academia se esforçam para enquadrar-se ao que está prescrito, quando esses pesquisadores atingem um nível de referência, estão a realizar o intencionalizado pelas políticas acadêmico-científicas; talvez estejam colocando-se como um potencial exemplar de sua posição no campo, referendada pela bolsa que recebem e por sua produção e produtividade objeto da avaliação CNPq (e Capes). Ao atingir este patamar, eles materializam a ideia "pesquisador em educação", fortalecendo-a como representação social e como medida de prestígio.

Considerando os quesitos enunciados e o objetivo deste estudo, analisamos a formação doutoral dos indivíduos selecionados. Vejam-se os Quadros 1 e 2.

\section{Quadro 1 - Formação doutoral dos Pesquisadores PEA}

\begin{tabular}{|c|c|c|}
\hline Pesquisador & Local & Década de início \\
\hline PEA01 & Reino Unido & 1980 \\
\hline PEA02 & França & 1960 \\
\hline PEA03 & Reino Unido & 1980 \\
\hline PEA04 & Brasil (Rio de Janeiro) & 1980 \\
\hline PEA05 & Brasil (São Paulo) & 1980 \\
\hline PEA06 & França & 1970 \\
\hline PEA07 & Brasil (São Paulo) & 1990 \\
\hline PEA08 & Brasil (São Paulo) & 1970 \\
\hline PEA09 & Espanha & 1960 \\
\hline
\end{tabular}

Fonte: Elaboração dos autores com base em Plataforma Lattes, CNPq (2015) 


\section{Quadro 2 - Formação doutoral dos Pesquisadores PEB}

\begin{tabular}{|c|c|c|}
\hline Pesquisador & Local & Década de início \\
\hline PEB01 & Brasil (São Paulo) & 1980 \\
\hline PEB02 & Brasil (São Paulo) & 1970 \\
\hline PEB03 & Brasil (São Paulo) & 1990 \\
\hline PEB04 & Brasil (São Paulo) & 1990 \\
\hline PEB05 & Brasil (Rio Grande do Sul) & 1980 \\
\hline PEB06 & Brasil (São Paulo) & 1970 \\
\hline PEB07 & Estados Unidos & 1970 \\
\hline$P E B 08$ & Brasil (Rio de Janeiro) & 1970 \\
\hline$P E B 09$ & Brasil (São Paulo) & 1980 \\
\hline$P E B 10$ & Brasil (Rio Grande do Sul) & 1980 \\
\hline PEB11 & Brasil (São Paulo) & 1980 \\
\hline$P E B 12$ & Brasil (São Paulo) & 1980 \\
\hline
\end{tabular}

Fonte: Elaboração dos autores com base em Plataforma Lattes, CNPq (2015)

Encontramos, aqui, aspectos interessantes ao adotarmos a abordagem de coorte, isto é, separando os pesquisadores estudados nos grupos PEA e PEB delimitados acima. Observamos que no primeiro grupo (Quadro 1), a metade havia cursado o doutorado no exterior, entre as décadas de 1960 e 1980. No grupo PEB, apenas um pesquisador se doutorou no estrangeiro, na década de 1970. Pareceu-nos significativo que aqueles pesquisadores que constituíram a coorte mais recente fizeram seu doutorado no Brasil (portanto, uma parcela de onze sobre um total de doze), apenas três não o fizeram no estado de São Paulo. A distribuição dos pesquisadores, aliás, representa certo deslocamento do centro de gravidade do eixo Rio de Janeiro - São Paulo, ainda que com um forte vetor ligado a esse último estado.

Examinamos em seguida, a produção desses pesquisadores, segundo os dois grupos definidos, demonstrada nos veículos tradicionais de publicação científica: artigos, capítulos de livros, livros (obras integrais) e organização de livros (coletâneas) para o período de 2005-2014 e o total de publicações em suas carreiras, segundo o registrado nos Currículos Lattes. Ressalvamos que, no caso de reedições, contabilizamos apenas a edição mais atual registrada na Plataforma Lattes. As Tabelas 1 e 2, a seguir, mostram essas produções. 
Tabela 1 -Artigos, capítulos e livros dos Pesquisadores PEA em dois períodos

\begin{tabular}{|c|c|c|c|c|c|c|c|c|}
\hline \multirow{2}{*}{ Pesquisador } & \multicolumn{2}{|c|}{ Artigos } & \multicolumn{2}{c|}{ Capítulos } & \multicolumn{2}{c|}{ Livros } & \multicolumn{2}{c|}{ Livros Organizados } \\
\cline { 2 - 9 } & $\begin{array}{c}\mathbf{2 0 0 5 -} \\
\mathbf{2 0 1 4}\end{array}$ & $\begin{array}{c}\text { Durante } \\
\text { carreira }\end{array}$ & $\begin{array}{c}\mathbf{2 0 0 5 -} \\
\mathbf{2 0 1 4}\end{array}$ & $\begin{array}{c}\text { Durante } \\
\text { carreira }\end{array}$ & $\begin{array}{c}\mathbf{2 0 0 5 -} \\
\mathbf{2 0 1 4}\end{array}$ & $\begin{array}{c}\text { Durante } \\
\text { carreira }\end{array}$ & $\begin{array}{c}\mathbf{2 0 0 5 -} \\
\mathbf{2 0 1 4}\end{array}$ & $\begin{array}{c}\text { Durante } \\
\text { carreira }\end{array}$ \\
\hline PEA01 & 22 & 58 & 41 & 95 & 2 & 2 & 9 & 14 \\
\hline PEA02 & 25 & 66 & 23 & 52 & 4 & 7 & 0 & 0 \\
\hline PEA03 & 8 & 40 & 14 & 69 & 1 & 1 & 4 & 4 \\
\hline PEA04 & 26 & 97 & 32 & 77 & 3 & 5 & 10 & 16 \\
\hline PEA05 & 8 & 48 & 25 & 36 & 2 & 7 & 2 & 4 \\
\hline PEA06 & 24 & 33 & 64 & 113 & 9 & 12 & 14 & 18 \\
\hline PEA07 & 20 & 41 & 4 & 21 & 2 & 9 & 1 & 1 \\
\hline PEA08 & 8 & 61 & 39 & 82 & 3 & 9 & 13 & 13 \\
\hline PEA09 & 24 & 44 & 52 & 107 & 2 & 4 & 19 & 28 \\
\hline
\end{tabular}

Fonte: Elaboração dos autores com base em Plataforma Lattes, CNPq (2015)

Tabela 2 - Artigos, capítulos e livros dos Pesquisadores PEB em dois períodos

\begin{tabular}{|c|c|c|c|c|c|c|c|c|}
\hline \multirow{2}{*}{ Pesquisador } & \multicolumn{2}{|c|}{ Artigos } & \multicolumn{2}{c|}{ Capítulos } & \multicolumn{2}{c|}{ Livros } & \multicolumn{2}{c|}{ Livros Organizados } \\
\cline { 2 - 9 } & $\begin{array}{c}\mathbf{2 0 0 5 -} \\
\mathbf{2 0 1 4}\end{array}$ & $\begin{array}{c}\text { Durante } \\
\text { carreira }\end{array}$ & $\begin{array}{c}\mathbf{2 0 0 5 -} \\
\mathbf{2 0 1 4}\end{array}$ & $\begin{array}{c}\text { Durante } \\
\text { carreira }\end{array}$ & $\begin{array}{c}\mathbf{2 0 0 5 -} \\
\mathbf{2 0 1 4}\end{array}$ & $\begin{array}{c}\text { Durante } \\
\text { carreira }\end{array}$ & $\begin{array}{c}\mathbf{2 0 0 5 -} \\
\mathbf{2 0 1 4}\end{array}$ & $\begin{array}{c}\text { Durante } \\
\text { carreira }\end{array}$ \\
\hline PEB01 & 11 & 30 & 18 & 37 & 5 & 7 & 0 & 0 \\
\hline PEB02 & 11 & 120 & 18 & 67 & 5 & 12 & 0 & 0 \\
\hline PEB03 & 33 & 60 & 50 & 81 & 1 & 2 & 21 & 26 \\
\hline PEB04 & 33 & 77 & 39 & 51 & 5 & 13 & 3 & 4 \\
\hline PEB05 & 48 & 126 & 35 & 47 & 1 & 4 & 9 & 10 \\
\hline PEB06 & 26 & 58 & 51 & 89 & 2 & 5 & 10 & 12 \\
\hline PEB07 & 94 & 242 & 5 & 7 & 16 & 34 & 1 & 3 \\
\hline PEB08 & 24 & 49 & 45 & 67 & 3 & 3 & 7 & 8 \\
\hline PEB09 & 35 & 74 & 59 & 90 & 2 & 7 & 10 & 12 \\
\hline PEB10 & 36 & 101 & 70 & 123 & 2 & 9 & 19 & 30 \\
\hline PEB11 & 18 & 34 & 13 & 30 & 7 & 7 & 1 & 1 \\
\hline PEB12 & 81 & 116 & 40 & 51 & 3 & 4 & 5 & 9 \\
\hline
\end{tabular}

Fonte: Elaboração dos autores com base em Plataforma Lattes, CNPq (2015)

Inicialmente, para o período 2005-2014, verificamos um maior número de artigos produzidos pela coorte $\mathrm{PEB}$ em relação à $\mathrm{PEA}$, com médias respectivas de 37,5 e 18,3. Essa diferença não parece ser tão significativa no que tange à 
produção de capítulos. Ademais, para vários pesquisadores, a produção em capítulos de livros supera a de artigos em periódicos. Também percebemos que, na soma de todos os tipos de publicações no decênio destacado, a produção do grupo PEB é mais numerosa do que a do grupo PEA, com uma média de 85,8 e 62,1 produtos, respectivamente. Evidencia-se também que há uma diferença no número de livros organizados.

Para além da produção científica, verificamos a participação dos pesquisadores em posições de chefia dentro da academia, como coordenação de programa de pós-graduação (PPG), chefia de departamento e direção de unidade acadêmica ou pró-reitoria ao longo de todas suas carreiras. Computamos também o exercício de funções ou cargos correlatos, tais como vice-coordenador, coordenador-adjunto, cocoordenador, subchefe, vice-pró-reitor e vice-diretor.

\section{Tabela 3 - Anos de atuação em cargos/funções na carreira dos Pesquisadores PEA}

\begin{tabular}{|c|c|c|c|}
\hline Pesquisador & $\begin{array}{c}\text { Coordenação } \\
\text { PPG }\end{array}$ & $\begin{array}{c}\text { Chefia } \\
\text { Departamento }\end{array}$ & $\begin{array}{c}\text { Direção de Unidade ou } \\
\text { Pró-Reitoria }\end{array}$ \\
\hline PEA01 & 14 & - & 5 \\
\hline PEA02 & - & 3 & - \\
\hline PEA03 & 4 & 6 & - \\
\hline PEA04 & 3 & - & - \\
\hline PEA05 & - & 7 & 5 \\
\hline PEA06 & 3 & 2 & - \\
\hline PEA07 & - & 3 & 9 \\
\hline PEA08 & 3 & 8 & - \\
\hline PEA09 & - & - & - \\
\hline
\end{tabular}

Fonte: Elaboração dos autores com base em Plataforma Lattes, CNPq (2015) 


\section{Tabela 4 - Anos de atuação em cargos/funções na carreira dos Pesquisadores PEB}

\begin{tabular}{|c|c|c|c|}
\hline Pesquisador & $\begin{array}{c}\text { Coordenação } \\
\text { PPG }\end{array}$ & $\begin{array}{c}\text { Chefia } \\
\text { Departamento }\end{array}$ & $\begin{array}{c}\text { Direção de Unidade ou } \\
\text { Pró-Reitoria }\end{array}$ \\
\hline PEB01 & - & - & 12 \\
\hline PEB02 & 8 & - & 4 \\
\hline PEB03 & - & 5 & - \\
\hline PEB04 & 7 & - & 5 \\
\hline PEB05 & - & 4 & 15 \\
\hline PEB06 & - & 3 & 3 \\
\hline PEB07 & 18 & 1 & 4 \\
\hline PEB08 & 5 & 7 & - \\
\hline PEB09 & 4 & - & 3 \\
\hline$P E B 10$ & 7 & - & 5 \\
\hline PEB11 & - & - & - \\
\hline$P E B 12$ & 18 & 6 & 4 \\
\hline
\end{tabular}

Fonte: Elaboração dos autores com base em Plataforma Lattes, CNPq (2015)

Percebemos uma diversidade na ocupação de cargos ou funções de chefia, tanto no que diz respeito às posições ocupadas quanto ao período durante o qual os pesquisadores ocuparam tais cargos e funções. Ao mesmo tempo, as diferenças parecem não ser importantes entre os grupos PEA e PEB quando se considera o número proporcional de pesquisadores que atuaram nessas posições em cada grupo. Já com relação ao tempo dedicado a essas atividades, para a chefia de departamentos, PEA apresenta uma média de 3,2 anos, sutilmente maior em relação a 2,2, média apresentada pelo grupo PEB. Quanto à coordenação de PPGs e à direção de unidades acadêmicas e de pró-reitorias, encontramos para o grupo PEB uma média de anos de exercício que margeiam o dobro daquelas obtidas para PEA: 5,6 e 4,6 em oposição a 3 e 2,1, respectivamente.

As Tabelas 5 e 6 registram a atuação dos pesquisadores como membros de comissões em organismos estatais de fomento e regulação da pesquisa e da pós-graduação. Envolvem tanto agências estaduais quanto federais. No caso de desempenho concomitante em mais de uma instituição, somamos igualmente os períodos de exercício. 
Tabela 5 - Atuação dos Pesquisadores PEA em agência de fomento ou regulação

\begin{tabular}{|c|c|}
\hline Pesquisador & Anos \\
\hline PEA01 & 13 \\
\hline PEA02 & - \\
\hline PEA03 & - \\
\hline PEA04 & 5 \\
\hline PEA05 & 15 \\
\hline PEA06 & - \\
\hline PEA07 & 37 \\
\hline PEA08 & - \\
\hline PEA09 & - \\
\hline
\end{tabular}

Fonte: Elaboração dos autores com base em Plataforma Lattes, CNPq (2015)

Tabela 6 - Atuação dos Pesquisadores PEB em agência de fomento ou regulação

\begin{tabular}{|c|c|}
\hline Pesquisador & Anos \\
\hline PEB01 & 4 \\
\hline PEB02 & 25 \\
\hline PEB03 & - \\
\hline PEB04 & 12 \\
\hline PEB05 & 25 \\
\hline PEB06 & - \\
\hline PEB07 & 16 \\
\hline PEB08 & 5 \\
\hline PEB09 & 11 \\
\hline PEB10 & 5 \\
\hline PEB11 & 2 \\
\hline PEB12 & 7 \\
\hline
\end{tabular}

Fonte: Elaboração dos autores com base em Plataforma Lattes, CNPq (2015)

A participação dos pesquisadores em comissões de órgãos de fomento e regulação parece ser uma tendência significativa entre aqueles que atingem o nível de referência da bolsa de produtividade de mais alto nível. Nota-se a presença de pesquisadores em múltiplas agências, ou por períodos prolongados, totalizando uma grande dedicação a esse tipo de atividade, especialmente em PEA07, PEB02 
e PEB05. Como em outras categorias de análise, a mobilização é maior em PEB do que em PEA. Se neste grupo, menos da metade dos pesquisadores registra atuação nesse tipo de organismo, naquele, apenas dois pesquisadores não o fazem.

O conjunto de dados coletados, bem como a próprio processo de coleta pela análise dos currículos, permite afirmar, ainda, que, na relação entre os pesquisadores que compõem o grupo de novos classificados (identificados em nossa pesquisa em 2015) pelo CNPq e os abordados na primeira fase da pesquisa (identificados como bolsistas em 2010), há mudanças na estratégia de pontuação das atividades segundo os registros encontrados na Plataforma Lattes. Esse dado diferenciado remete à ideia de que as próprias atividades são valorizadas de forma diferente, seja por exigência de avaliações externas, seja porque o pesquisador se percebe em um cenário modificado, no qual a competitividade entre pares está mais intensamente presente. O fato é que, olhando-se desde os currículos Lattes, há mudanças sobre o modo como se é pesquisador de referência ao longo dos anos no subcampo da educação.

\section{DISCUSSÃO DOS RESULTADOS}

A análise comparativa dos currículos dos grupos de pesquisadores fez emergir algumas tendências, características gerais que passamos a comentar. Entre elas, verificamos que a produção de conhecimento registrada em publicações no período de dez anos em que concentramos a análise (2005-2014) corresponde, em muitos casos, a mais da metade da produção do pesquisador em toda a sua carreira, mesmo para aqueles pesquisadores que já eram doutores na década de 1980. Entendemos que isso ocorre por ser esse o período em que se intensificaram as políticas científicas e avaliativas, tanto em termos de incentivos quanto de sanções (CAPES, 2004; 2013). Nessa conjuntura, na medida em que houve maior exigência de produção caracterizada por contagem de publicações científicas, a estratégia de sustentar a posição apenas pela autoridade tradicional no subcampo parece relativamente menos presente ou, ao menos, faz-se acompanhar da disputa por capital científico puro e político visto por meio do aumento do número de publicações ou ocupação de espaços. Assim, conforme a avaliação foi incidindo sobre a atribuição das bolsas de produtividade, um novo perfil, de atuação mais visível em produtos, parece ter-se tornado mais saliente, como se observa na coorte PEB.

Essa observação encontra respaldo em vários trabalhos e, também, na teorização de Bourdieu $(1983$; 2004) acerca da competitividade no campo. Por um lado, a expansão do campo científico brasileiro e, com ele, a do subcampo da educação, aumentou o número de pesquisadores com bolsa de produtividade de 
alto nível, caracterizando uma modificação horizontal nas estruturas de relações do campo. Isso fez com que o pesquisador de referência passasse a ter maior número de pares. Por outro lado, em termos verticais, a intensificação dos critérios de avaliação faz com que o pesquisador que deseja ascender à categoria precise apresentar um perfil cada vez mais competitivo com base nos critérios definidos pelos pares por meio da agência de fomento (CNPq) para o campo. Afinal, o número de bolsas de produtividade disponível é limitado e não se expande em proporção ao crescimento do campo, fazendo com que existam possibilidades limitadas para os aspirantes. Uma vez que os pesquisadores mais prestigiosos permanecem longo tempo na mesma posição, torna-se ainda mais difícil ao pesquisador médio em Educação acessar tal posição.

Outro elemento significativo nessa dinâmica concorrencial é a produção de conhecimento veiculada em publicações, especialmente de artigos em periódicos. Estamos aqui diante de uma forma de capital científico puro. Aparentemente aumentou o quantum de capital necessário para passar a ser considerado pesquisador de referência na área.

Com relação à atuação em posições de gestão acadêmica, os dados parecem sinalizar que, conforme os departamentos vão tornando-se instâncias mais burocráticas e a chefia de departamento se desvincula da imagem de liderança acadêmica, essa posição vai tornando-se menos atrativa como recurso de capital científico-político. O mesmo não ocorre com a coordenação de programas de pós-graduação ou com a direção de unidades acadêmicas e o pró-reitorado, posições que guardam um caráter distintivo.

Podemos ter como hipótese que a posição de coordenador de PPG, em comparação com a de chefe de departamento, guarda maior associação com o capital científico puro: a pós-graduação é o espaço mais relacionado com a pesquisa. Ela também confere maior capital científico político: os PPGs tendem a ter maior tipificação, articulação e poder no subcampo nacional da Educação do que os departamentos. De outra parte, as posições de liderança em unidades acadêmicas e pró-reitorias concedem prestígio e influência superiores aos das chefias de departamento, bem como um domínio maior sobre os recursos do campo científico no nível institucional. Assim, se consideramos que as estratégias empregadas pelos pesquisadores na constituição de suas carreiras não são apenas cálculos racionais, mas envolvem um domínio prático da lógica do campo, os diferentes perfis encontrados entre as coortes PEA e PEB permitem levantar a hipótese de modificações no habitus. Haveria padrões de comportamento e esquemas de ação diferenciados entre os pesquisadores conforme o período de acesso ao subcampo. A busca por posições no período mais recente demandaria 
novas estratégias de competição, o que talvez possamos denominar o competitio ${ }^{1}$ da educação, talvez um amálgama de competição com competência como o sugere o termo latino que lhe dá origem.

De todo modo, o aumento das posições de coordenação de PPG em relação à de chefia de departamento pode também ser uma repercussão de outras dinâmicas da educação superior no Brasil na última década. Mais especificamente, referimo-nos ao fato de que, na última década, proporcionalmente, a atividade pós-graduada se expandiu mais do que sua estrutura institucional, se a lemos a partir dos números de cursos stricto sensu e de universidades criadas no período.

Se olharmos, para além da atuação no âmbito da gestão universitária, as atividades de cunho político no interior do campo acadêmico-científico da educação, também é possível apontar transformações. As tabelas 5 e 6 sinalizam uma modificação do perfil de participação dos pesquisadores, estabelecidos e de nova geração, em agências de fomento e regulação. Entre PEB há uma maior proporção de indivíduos que tomam parte nesses organismos (dez entre doze), comparativamente aos PEA, cuja participação ficava concentrada em poucos indivíduos (quatro entre nove), sendo que três deles participaram por mais de dez anos, em agências estaduais e federais. Percebe-se, portanto, que esse tipo de participação em posições de tomada de decisão sobre política científica torna-se mais difusa.

Por um lado, isso responde ao crescimento do número de atores no campo e pode ser lido como forma de democratização na ocupação dessas posições. Por outro lado, aqueles que acessam essas posições têm um perfil mais aderente ao competitio em termos de produtividade, em publicações e em gestão. Eles também tendem a definir as práticas avaliativas e, com elas, o novo perfil do pesquisador em educação a ser fomentado. $\mathrm{O}$ terreno parece se preparar para um acirramento das exigências.

Alteram-se as condições para a produção da legitimidade no campo hoje; elas não indicam alterações na forma como o subcampo se insere no campo científica-acadêmico mais amplo. Tais mudanças guardam relação com políticas acadêmico-científicas mais amplas. Assim, sem que se avance numa maior delimitação do campo, alteram-se os indícios de estratégias de composição de capital científico para legitimação como pesquisador de destaque no subcampo da educação.

1 Competência e competição derivam da forma latina competentia, competitio - capacidade, capabilidade, aptidão, idoneidade e competição (CUNHA, 1986). 


\section{CONSIDERAÇÕES FINAIS}

Estamos atentos ao que reporta Caria (2014, p. 805), quando se trata de conhecimento e campo científico, ou seja,

O que decide sobre o uso que os profissionais fazem com o conhecimento abstracto é o conteúdo e o significado que lhe atribuem, ou que são constrangidos a atribuir pelo poder institucional dominante: serem instrumentos passivos de uma política ou de missões institucionais dadas, ou serem sujeitos activos, não reprodutivos, críticos da ordem institucional vigente.

Estas opções contraditórias, apontadas por Caria poderiam, no entanto, estar entranhadas nos saberes ético-profissionais dos pesquisadores. Percebemos, porém, que há um distanciamento entre aquilo que é praticado pelos pesquisadores de referência em educação no Brasil em relação ao que é exposto na teoria sociológica sobre o campo científico.

Em primeiro lugar, os dados coletados confirmam o já registrado a partir da primeira etapa da pesquisa, mas também a partir da teoria (FIORIN, 2007) com relação à tendência das ciências humanas e sociais de apresentar o conhecimento que produzem, por meio de uma distribuição de suas publicações mais em livros do que em artigos.

Em segundo lugar, quando falamos em produção do conhecimento científico em educação, o campo científico vem sempre adjetivado: acadêmicocientífico. Isso responde a uma lógica mais ampla, sistêmica, do Brasil, em que a pesquisa científica é realizada quase em sua totalidade nas Instituições de Educação Superior e, dentre elas, em sua maioria, na pós-graduação das universidades. Ainda, considerando que a legislação nacional prevê apenas a atividade de pesquisa associada à docência nos planos de carreira dessas instituições, quase todos os pesquisadores em educação no Brasil são também professores. Assim, os pesquisadores, em especial do subcampo da educação, estão imersos em seu próprio objeto de estudo.

Considera-se, então, que esse subcampo acadêmico-científico éatravessado por uma racionalidade prática, uma diferença, ligada a um efeito imediato nas redes escolares, e essa relação com as escolas, instâncias governamentais e instâncias administrativas das instituições escolares compõem uma forma de capital simbólico própria com um valor/uma utilidade que pode ser equivalente ao que, nos outros campos, é representado pelo capital científico tradicional. Esse envolvimento também impacta uma estruturação menos rígida do campo científico, de suas 
linguagens disciplinares e de seus códigos sociais, tornando-o mais permeável e menos delimitado em termos epistemológicos. Essas características, por sua vez, traduzem-se em desafios para o reconhecimento social da educação como ciência.

A análise dos dados permite afirmar que houve uma mudança na composição do capital acadêmico-científico individual dos atores, provavelmente induzida pelas políticas públicas de avaliação. A emergência de novos perfis de pesquisadores sugere a existência de uma reestruturação de regras do campo acadêmico-científico da educação. Identificamos delimitações e sinalizações sobre mudanças no interior do subcampo as quais evidenciam modificações em fatores que contribuem para a constituição da legitimidade do pesquisador de prestígio.

A ordem institucional delimitadora de campo e subcampo seria um objeto para explorações futuras, tendo por base, por exemplo, as dinâmicas de financiamento da pesquisa, na capacidade dos pesquisadores de disputar recursos, em diferentes níveis: tanto no montante da riqueza nacional que se destina à atividade científica; na distribuição desse montante entre as áreas de conhecimento; como entre os próprios indivíduos dentro de cada área ou subcampo.

\section{REFERÊNCIAS}

BARATA, Rita B. et al. The configuration of the Brazilian scientific field. Anais da Academia Brasileira de Ciências, Rio de Janeiro, v. 86, n. 1, p. 505-521, mar. 2014.

BECK, John; YOUNG, MichaelF.D. Investida contra as profissões e reestruturação das identidades acadêmicas e profissionais. Cadernos de Pesquisa, São Paulo, v. 38, n. 135, p. 587-609, set./dez. 2008.

BOURDIEU, Pierre. A Distinção: crítica social do julgamento. Porto Alegre: Zouk, 2011.

BOURDIEU, Pierre. Os usos sociais da ciência: por uma sociologia clínica do campo científico. São Paulo: Unesp, 2004.

BOURDIEU, Pierre. Intelectuales, política y poder. Buenos Aires: Eudeba, 2000.

BOURDIEU, Pierre. Razões práticas: sobre a teoria da ação. Campinas: Papirus, 1996. 
BOURDIEU, Pierre. O Campo Científico. In: ORTIZ, Renato (Org.). Pierre Bourdieu. São Paulo: Ática, 1983.

CAPES - Coordenação de Aperfeiçoamento de Pessoal de Nível Superior. Comissão Especial de Acompanhamento do PNPG 2011-2020 e Elaboração da Agenda Nacional de Pesquisa. Relatório Final: 2013. Brasília: Capes, 2013. Disponível em: <http://capes.gov.br/images/stories/download/PNPGRelatorio-Final-11-12-2013.pdf>. Acesso em: 27 abr. 2016.

CAPES - Coordenação de Aperfeiçoamento de Pessoal de Nível Superior. Plano nacional de pós-graduação (PNPG) 2005-2010. Brasília: Capes, 2004. Disponível em: < https://www.capes.gov.br/images/stories/download/editais/ PNPG_2005_2010.pdf>. Acesso em: 27 abr. 2016.

CAPES - Coordenação de Aperfeiçoamento de Pessoal de Nível Superior. Geocapes. Disponível em: <http://geocapes.capes.gov.br/geocapes2/>. Acesso em: 27 abr. 2016.

CAREGNATO, Célia Elizabete; LEITE, Denise Balarine Cavalheiro; SFREDO MIORANDO, Bernardo. Pesquisadores e legitimidade científica no campo da educação. Linhas Críticas, Brasília, v. 22, n. 47, p. 189-209, jan./abr. 2016.

CARIA, Telmo H. Hierarquias de conhecimento e saber profissional. Cadernos de Pesquisa, São Paulo, v. 44, n. 154, p. 798-826, out/dez. 2014.

CNPQ - Conselho Nacional de Desenvolvimento Científico e Tecnológico. Anexo III: Produtividade em Pesquisa - PQ. Resolução Normativa n. 28/2015. Brasília, 2015. Disponível em: <http://www.cnpq.br/web/guest/view/-/ journal_content/56_INSTANCE_0oED/10157/2958271>. Acesso em: 27 abr. 2016.

CUNHA, Antônio Geraldo da. Dicionário Etimológico Nova Fronteira da Língua Portuguesa. 2. Ed. Rio de janeiro: Nova Fronteira, 1986.

DALBOSCO, Cláudio A. Pesquisa educacional e experiência humana na perspectiva hermenêutica. Cadernos de Pesquisa, São Paulo, v. 44, n. 154, p. 1028-1051, out./dez. 2014. 
FARIA FILHO, Luciano Mendes de. Avaliação da pós-graduação em Educação: questões, dilemas e algumas proposições. Educação em Foco, Belo Horizonte, ano 19, n. 27, p. 173-205, jan./abr. 2016.

FIORIN, José Luiz. Internacionalização da Produção Científica. Revista Brasileira da Pós-Graduação, Brasília, v. 4, n. 8, p. 263-281, dez. 2007.

HORTA, José Silvério B.; MORAES, Maria Célia M. O sistema CAPES de avaliação da pós-graduação: da área da Educação à grande área de Ciências Humanas. Revista Brasileira de Educação, Rio de Janeiro, n. 30, p. 95-116, set./dez. 2005.

JAPIASSU, Hilton. A crise das Ciências Humanas. São Paulo: Cortez, 2013.

LEITE, Denise. Avaliação institucional, reforma e redesenho capitalista das universidades. Avaliação, Campinas, v. 7, n. 2, p. 29-48, 2002.

LEITE, Denise. et al. Avaliação de Redes de Pesquisa e Colaboração. Avaliação, Sorocaba, v. 19, n. 1, p. 291-312, mar. 2014.

KUENZER, Acácia Z.; MORAES, Maria Célia M. Temas e tramas da pósgraduação em Educação. Educação e Sociedade, Campinas, v. 26, n. 93, p. 1341-1363, set./dez., 2005.

SETTON, Maria da Graça Jacintho. A teoria do habitus em Pierre Bourdieu: uma leitura contemporânea. Revista Brasileira de Educação, Rio de Janeiro, n. 20, p. 60-70, maio-ago. 2002.

RISTOFF, Dilvo; BIANCHETTI, Lucídio. A pós-graduação e suas interlocuções com a educação básica: (des)encontros históricos e manutenção do apartheid socioeducacional. Avaliação, Sorocaba, v. 17, n. 3, p. 787-824, nov. 2012.

CÉlia ElizABete CAREgnATO possui Mestrado em Ciência Política pela UFRGS (1992) e Doutorado em Educação pela UFRGS (2004). É professora associada na Universidade Federal do Rio Grande do Sul, membro do corpo permanente do Programa de Pós-Graduação em Educação da mesma Universidade, sendo também membro da Comissão Coordenadora do Programa 
(2017-2019). Pesquisa e orienta pesquisas, a partir da Sociologia da Educação, sobre temas da educação superior e da educação de nível médio. Também trabalha com aspectos sociológicos e educacionais no âmbito do ensino de Sociologia. E-mail: celia.caregnato@gmail.com

BERNARDO SFREDO MIORANDO é Mestre em Educação. Doutorando no Programa de Pós-Graduação em Educação da Universidade Federal do Rio Grande do Sul (PPGEdu/UFRGS), Porto Alegre, Rio Grande do Sul, Brasil. Membro do Grupo de Pesquisa Inovação e Avaliação na Universidade (InovAval). E-mail: bernardo.sfredo@gmail.com

DENISE LEITE é Doutora em Ciências Humanas. Professora Permanente do Programa de Pós-Graduação em Educação da Universidade Federal do Rio Grande do Sul (PPGEdu/UFRGS), Porto Alegre, Rio Grande do Sul, Brasil. Membro do Grupo de Pesquisa Inovação e Avaliação na Universidade (InovAval). Bolsista de Produtividade CNPq. E-mail: denise.leite@pq.cnpq.br

Recebido em maio de 2017 Aprovado em outubro de 2017 